\title{
Conservative pharmacotherapy vs. staged percutaneous coronary intervention for non-culprit vessels in patients with ST-segment elevation myocardial infarction
}

\author{
BO ZHAO, JIANJUN PENG, LIHUI REN, LICHENG LEI, ZUOYAN WANG and HUIMING YE \\ Department of Cardiology, Beijing Shijitan Hospital, Capital Medical University, Beijing 100038, P.R. China
}

Received November 25, 2015; Accepted September 9, 2016

DOI: $10.3892 /$ etm.2016.3895

\begin{abstract}
The present study aimed to compare the effect of conservative pharmacotherapy (CP) and staged percutaneous coronary intervention (SPCI) on significant non-culprit vessels in patients with ST-segment elevation myocardial infarction (STEMI). A total of 266 male and 40 female patients were divided into two groups following their first successful PCI treatment: i) Patients in the complete revascularization (CR) group undergoing SPCI; and ii) patients in the CP group undergoing CP. Follow-up data were collected at 180 or 360 days after surgery to compare the rates of major adverse cardiovascular events (MACE), recurrent myocardial infarction, recurrent angina pectoris and MACE-free survival rates between the two groups. The rate of MACE in the CP group was higher compared with that in the CR group at the 360-day follow-up (6.1 vs. $12.7 \%$; $\mathrm{P}=0.05$ ), and the same was reflected in the rate of recurrent myocardial infarction (10.1 vs. $4.1 \%$; $\mathrm{P}=0.04$ ). The rate of recurrent angina pectoris in the $\mathrm{CP}$ group was significantly higher compared with that in CR group at the 180 -day (13.9 vs. $5.4 \% ; \mathrm{P}=0.012)$ and 360 -day follow-up (18.4 vs. $8.1 \%$; $\mathrm{P}=0.009)$. The MACE-free survival rate of patients was significantly higher in the CR group compared with that in the CP group at the 360-day follow-up (93.9\% vs. $87.3 \%, \mathrm{P}<0.05)$. In conclusion, the SPCI of non-culprit vessels in patients with STEMI is associated with better clinical outcomes than CP.
\end{abstract}

\section{Introduction}

ST-elevation myocardial infarction (STEMI) is defined as a clinical characteristic symptom of myocardial ischemia. It is association with persistent electrocardiographic ST elevation and subsequent release of biomarkers of myocardial necrosis (1).

Correspondence to: Dr Jianjun Peng, Department of Cardiology, Beijing Shijitan Hospital, Capital Medical University, 10 Tieyi Road, Beijing 100038, P.R. China

E-mail: jianjunpengg@163.com

Key words: staged percutaneous coronary intervention, non-culprit lesions, ST-segment elevation myocardial infarction, major adverse cardiovascular events
A high percentage (40-70\%) of patients presenting with STEMI have been diagnosed with multivessel coronary artery disease (CAD) with $\geq 1$ additional severe non-infarct-related lesion in an artery $(2,3)$. These patients have worse outcomes with $>2$-fold increase in mortality at 1 year compared with patients who have single vessel disease $(4,5)$.

Previous studies have been reported the treatment of STEMI. For example, primary percutaneous coronary intervention (PPCI) has been considered as the treatment of choice for patients with STEMI (6). In addition, complete revascularization during PPCI for STEMI has been verified safely with improved clinical results (7). Other studies have suggested that medical therapy with fondaparinux (8) or aspirin (with the addition of clopidogrel) (9) is effective and can reduce risk of complications and mortality. However, it still remains controversial regarding the optimal management of patients with STEMI and multivessel CAD in spite of the recent Preventive Angioplasty in Myocardial Infarction (PRAMI) trial and Complete vs. Lesion-Only Primary PCI trial (CvLPRIT) $(10,11)$.

The present prospective, open-label, randomized study aimed to further evaluate the effect of conservative pharmacotherapy $(\mathrm{CP})$ and staged percutaneous coronary intervention (SPCI) on significant non-culprit vessel lesions following PPCI in patients with STEMI by comparing the incidence rates of major adverse cardiovascular events (MACE), recurrent myocardial infarction, recurrent angina pectoris and MACE-free survival rates at a 180- and 360-day follow-up.

\section{Subjects and methods}

Subjects and criteria. This prospective study enrolled a total of 306 patients with acute STEMI (266 male and 40 female; mean age, $56.4 \pm 10$ years) treated with PPCI in Beijing Shijitan Hospital (Beijing, China) between April 2011 and December 2012. Patients were included on the basis of the following criteria as described previously (12-14): i) Patients aged between 18 and 75 years; ii) patients underwent continuous ischemic chest pain for $\geq 30 \mathrm{~min}$; iii) the electrocardiogram examination revealed ST-elevation $\geq 0.2 \mathrm{mV}$ in leads $\mathrm{V} 2$ and $\mathrm{V} 3$ or ST-elevation $\geq 0.1 \mathrm{mV}$ in at least two other continuous leads, and cardiac troponin-I (cTn-I)-elevation $>0.05 \mathrm{ng} / \mathrm{ml}$; iv) the coronary arteriography performed within $12 \mathrm{~h}$ following the onset of symptoms indicated thrombolysis in myocardial 
infarction bleeding grade 0-1 in culprit vessels; v) the PPCI was performed only in culprit vessels; and vi) the presence of coronary arteriography corroborated lesions in non-culprit vessel. Non-culprit lesions were defined as angiostenosis $\geq 70 \%$ in one or more coronary vessels with a diameter $\geq 2 \mathrm{~mm}$ vessels other than culprit vessels.

Patients were excluded for the following criteria: i) Patients with left main coronary artery disease, cardiogenic shock or complete left bundle branch block; ii) PPCI performed for both culprit and non-culprit vessels at the same time or a PPCI performance failure; iii) patients who have experienced hemodynamic instability or spontaneous ischemia following PPCI; iv) lesions and angiostenosis $\geq 70 \%$ in vessels remaining following SPCI; v) patients who had a history of coronary artery bypass grafting (CABG) or chronic cardiac failure; and vi) bleeding corporeality, prior administration of thrombolytic therapy, known thrombopenia or leucopenia, sever liver and renal function abnormalities, active infection, immune system and connective tissue diseases, known contraindications to aspirin or heparin, pregnancy, life expectancy $<1$ year, major operation within 3 months, uncontrolled hypertension, a history of ischemic or hemorrhagic stroke, intracranial diseases including aneurysm and arteriovenous malformation within 30 days, extensive trauma within 6 weeks, oral anticoagulant therapy, severe ongoing myocardial infarction-related complications or perioperative mortality.

The ethical committee of Beijing Shijitan Hospital approved the study protocol and detailed informed consent was obtained from all of the patients or their family members.

Study procedures and drug treatment. Patients were randomly divided into $\mathrm{CR}$ and $\mathrm{CP}$ groups using a table of random digits. Patients in the CR group underwent SPCI for non-culprit lesions after 7-10 days of PPCI. The PPCI was performed according to standard techniques, during which a drug-eluting stent was used. Patients in the CP group were only treated with CP following PPCI. Echocardiography was performed in both groups using a Doppler echocardiograph (Vivid; GE Healthcare Bio-Sciences, Pittsburgh, PA, USA), and left ventricular function with preserved ejection fraction was diagnosed according to the study of Paulus et al (15). Then, an intra-aortic balloon pump was inserted in patients with poor left ventricular function at the lesion site of infarct-related artery following PPCI. In addition, all patients received a single dose of oral aspirin (300 mg; Bayer Healthcare Co., Ltd., Beijing, China) and clopidogrel (300 mg; Sanofi-Aventis, Paris, France) prior to PPCI, and $100 \mathrm{mg} / \mathrm{d}$ aspirin, $75 \mathrm{mg} / \mathrm{d}$ clopidogrel orally for $\geq 1$ year. Low molecular weight heparin was administered for 3 days following PPCI, as well as other drugs such as statins, $\beta$ receptor blocker, angiotensin-converting enzyme inhibitor/angiotensin II receptor blocker, calcium antagonists, nitrates or tirofiban.

Experimental endpoints. The primary endpoints were adjudicated by the incidence of MACE at the 180- and 360-day follow-up, including cardiac death, recurrent myocardial infarction and repeated revascularization of the target-vessel. The secondary endpoints were the recurrence of angina pectoris, newly developed heart failure and bleeding events, and MACE-free survival at the 180- and 360-day follow-up.
All the events were adjudicated according to the Bleeding Academic Research Consortium proposed standardized bleeding definitions (16).

Data collection and follow-up. Baseline demographics, including gender, age, height, weight, case history, previous medication and other clinical data of patients were collected. The content of cTn-I was recorded prior to PPCI, and thereafter every $8 \mathrm{~h}$ after the procedure. The levels of fasting blood glucose, hepatorenal function, blood fat, C-reactive protein and brain natriuretic peptide were detected on the second day following PPCI. The cumulative incidence of MACE, mortality, repeated revascularization of the target-vessel, recurrent myocardial infarction, recurrent angina pectoris, new heart failure and major bleeding were recorded at the 180- and 360-day follow-up. Follow-up was performed by interview.

Statistical analysis. Qualitative data are expressed as percentages, and differences between groups were analyzed using Fisher's test. Quantitative data showing normal distribution are expressed as the mean \pm standard deviation, and differences between the two groups were determined by independent t-test. Quantitative data showing abnormal distribution were expressed by median (interquartile range), and differences between groups were determined by the Mann-Whitney U-test. The survival curves during the 180- and 360-day follow-up were plotted using the Kaplan-Meier method and the analyses were determined using pairwise log-rank test. All statistical tests were two-sided and the analyses were performed using SPSS version 18.0 (SPSS, Inc., Chicago, IL, USA). P<0.05 was considered to indicate a statistically significant difference.

\section{Results}

General characteristics and examination of patients. A total of 306 patients in the trial were divided into two groups following PPCI: 148 patients (48\%) in the CR group, and 158 patients (52\%) in the CP group. As shown in Table I, baseline clinical characteristics were similar in the two groups, except for the mean age $(58 \pm 10$ vs. $55 \pm 9$ years; $\mathrm{P}=0.006)$, patient weight $(75 \pm 13$ vs. $72 \pm 10 \mathrm{~kg} ; \mathrm{P}=0.024)$, length of hospital stay $(10 \pm 6$ vs. $8 \pm 7$ days; $\mathrm{P}=0.008)$, disease time $(6 \pm 4$ vs. $5 \pm 3 \mathrm{~h} ; \mathrm{P}=0.014)$, body temperature $\left(36.3 \pm 0.3\right.$ vs. $\left.36.4 \pm 0.4^{\circ} \mathrm{C} ; \mathrm{P}=0.014\right)$ and left ventricular end-diastolic dimension (LVEDD; 50 \pm 4 vs. $48 \pm 4 \mathrm{~mm} ; \mathrm{P}<0.001)$ in the $\mathrm{CR}$ and $\mathrm{CP}$ groups, respectively. During the hospital stay, patients in the CR and CP groups received similar intra-aortic balloon counterpulsation and administration of drugs (Table II), except that significantly more CP patients were administered nitrates compared with the $\mathrm{CR}$ cases (94.3 vs. $75.7 \%$, respectively; $\mathrm{P}<0.001)$. The information collected prior to and following PPCI did not differ between the $\mathrm{CP}$ and $\mathrm{CR}$ groups (all P>0.05; Table III).

MACE and recurrent angina pectoris during follow-up. All patients were followed-up and the clinical outcomes of the 180- and 360-day follow-up after PPCI are presented in Table IV. The incidence of recurrent angina pectoris in the CP group was significantly higher compared with that in the CR group at the 180-day follow-up (13.9 vs. 5.4\%, respectively; 
Table I. Clinical characteristics of the patients at baseline.

\begin{tabular}{|c|c|c|c|}
\hline Characteristics & CR group & $\mathrm{CP}$ group & P-value \\
\hline Female, n (\%) & $22(14.9)$ & $18(11.4)$ & 0.368 \\
\hline Mean age, years & $58 \pm 10$ & $55 \pm 9$ & 0.006 \\
\hline Height, $\mathrm{cm}$ & $169 \pm 7$ & $169 \pm 7$ & 1.000 \\
\hline Weight, kg & $75 \pm 13$ & $72 \pm 10$ & 0.024 \\
\hline Smoking history, n (\%) & $100(67.6)$ & $108(68.4)$ & 0.883 \\
\hline Drinking history, n (\%) & $50(33.8)$ & $55(34.8)$ & 0.850 \\
\hline \multicolumn{4}{|l|}{ Case history, $\mathrm{n}(\%)$} \\
\hline Previous stenocardia & $76(51.4)$ & $80(50.6)$ & 0.900 \\
\hline Previous myocardial infarction & $2(1.4)$ & $3(1.9)$ & 0.706 \\
\hline Family history of coronary heart disease & $30(20.3)$ & $27(17.1)$ & 0.475 \\
\hline Hypertension & $86(58.1)$ & $80(50.6)$ & 0.190 \\
\hline Diabetes & $43(29.1)$ & $45(28.5)$ & 0.912 \\
\hline Hyperlipidemia & $72(48.6)$ & $76(48.1)$ & 0.924 \\
\hline Stroke & $8(5.4)$ & $8(5.1)$ & 0.893 \\
\hline Peripheral vascular disease & $2(1.4)$ & $4(2.5)$ & 0.740 \\
\hline Chronic renal insufficiency & $1(0.7)$ & $2(1.3)$ & 1.000 \\
\hline Alimentary tract hemorrhage & $4(2.7)$ & $4(2.5)$ & 1.000 \\
\hline \multicolumn{4}{|l|}{ Previous medical therapy, n (\%) } \\
\hline Aspirin & $21(14.2)$ & $16(10.1)$ & 0.276 \\
\hline Clopidogrel & $1(0.7)$ & $1(0.6)$ & 1.000 \\
\hline Warfarin & $1(0.7)$ & $1(0.6)$ & 1.000 \\
\hline$\beta$ blocker & $15(10.1)$ & $11(7.0)$ & 0.320 \\
\hline ACEI/ARB & $24(16.2)$ & $19(12.0)$ & 0.292 \\
\hline Statins & $10(6.8)$ & $13(8.2)$ & 0.626 \\
\hline Calcium antagonists & $32(21.6)$ & $27(17.1)$ & 0.315 \\
\hline Hospital stay, days & $10 \pm 6$ & $8 \pm 7$ & 0.008 \\
\hline Duration of disease, $\mathrm{h}$ & $6 \pm 4$ & $5 \pm 3$ & 0.0135 \\
\hline Killip grade III/IV, n (\%) & $2(1.4)$ & $3(1.9)$ & 1.000 \\
\hline Body temperature, ${ }^{\circ} \mathrm{C}$ & $36.3 \pm 0.3$ & $36.4 \pm 0.4$ & 0.014 \\
\hline Heart rate, times/min & $77 \pm 13$ & $80 \pm 14$ & 0.053 \\
\hline Respiration, times/min & $18 \pm 2$ & $18 \pm 2$ & 1.000 \\
\hline LVEF, \% & $54 \pm 8$ & $53 \pm 8$ & 0.275 \\
\hline LVEDD, mm & $50 \pm 4$ & $48 \pm 4$ & $<0.001$ \\
\hline \multicolumn{4}{|l|}{ Convict vessel site, n (\%) } \\
\hline $\mathrm{LAD}$ & $71(48.0)$ & $85(53.8)$ & 0.308 \\
\hline LCX & $9(6.1)$ & $10(6.3)$ & 0.928 \\
\hline RCA & $68(45.9)$ & $63(39.9)$ & 0.283 \\
\hline \multicolumn{4}{|l|}{ Non-culprit lesions, n (\%) } \\
\hline Single-vessel & 99 (66.9) & $105(66.5)$ & 0.936 \\
\hline Double-vessel & $49(33.1)$ & $53(33.5)$ & 0.936 \\
\hline Emergency stents & $1.3 \pm 0.6$ & $1.3 \pm 0.5$ & 1.000 \\
\hline Severe ventricular arrhythmias, n (\%) & $1(0.7)$ & $2(1.3)$ & 1.000 \\
\hline Slow blood flow or no reflow, n (\%) & $8(5.4)$ & $10(6.3)$ & 0.731 \\
\hline
\end{tabular}

Data are presented as percentage or mean \pm standard deviation. ACEI/ARB, angiotensin converting enzyme inhibitor/angiotensin receptor blocker; LVEF, left ventricular ejection fraction; LVEDD, left ventricular end diastolic diameter; LAD, left anterior descending coronary artery; LCX, left circumflex coronary artery; RCA, right coronary artery.

$\mathrm{P}=0.012)$ and the 360 -day follow-up (18.4 vs. $8.1 \%$, respectively; $\mathrm{P}=0.009)$. A total of 29 cases had developed MACE symptoms by the 360-day follow-up, and the incidence of
MACE in the CP group was significantly higher compared with that in the CR group (6.1 vs. $12.7 \%$; $=0.050)$, and the same tendency was detected in the incidence of recurrent 
Table II. Treatment administered during the hospital stay.

\begin{tabular}{|c|c|c|c|}
\hline Item & CR group & $\mathrm{CP}$ group & P-value \\
\hline \multicolumn{4}{|c|}{ Intra-aortic balloon counterpulsation } \\
\hline Case, $\mathrm{n}(\%)$ & $12(8.1)$ & $14(8.9)$ & 0.813 \\
\hline Time, h & $6.4 \pm 18.8$ & $10.4 \pm 28.2$ & 0.148 \\
\hline \multicolumn{4}{|l|}{ Medical therapy, n (\%) } \\
\hline Aspirin & $148(100)$ & $158(100)$ & - \\
\hline Clopidogrel & $148(100)$ & $158(100)$ & - \\
\hline Cilostazol & $2(1.4)$ & $2(1.3)$ & 1.000 \\
\hline Low molecular weight heparin & $100(67.6)$ & $101(63.9)$ & 0.502 \\
\hline$\beta$ receptor blocker & $128(86.5)$ & $135(85.4)$ & 0.793 \\
\hline ACEI/ARB & $125(84.5)$ & $137(86.7)$ & 0.575 \\
\hline Statins & $148(100)$ & $158(100)$ & - \\
\hline Calcium antagonists & $1(0.7)$ & $1(0.6)$ & 1.000 \\
\hline Nitrates & $112(75.7)$ & $149(94.3)$ & $<0.001$ \\
\hline Tirofiban & $50(33.8)$ & $55(34.8)$ & 0.850 \\
\hline
\end{tabular}

Data are presented as percentage or mean \pm standard deviation. ACEI, angiotensin-converting enzyme inhibitor; ARB, angiotensin II receptor blocker; CR, complete revascularization; CP, conservative pharmacotherapy.

Table III. Data collected prior to and following surgery.

\begin{tabular}{|c|c|c|c|}
\hline Terms & CR group & $\mathrm{CP}$ group & P-value \\
\hline \multicolumn{4}{|l|}{ Before surgery } \\
\hline AUC of CK-MB, $x 10^{3} \mathrm{ng} /\left(\mathrm{ml}^{*} \mathrm{~h}\right)$ & $5.7(4.0-10.9)$ & $5.5(3.7-8.9)$ & 0.473 \\
\hline AUC of cTnI, x10³ ng/(ml*h) & $2.9(1.3-5.4)$ & $2.8(1.6-4.7)$ & 0.891 \\
\hline Peak of CK-MB, ng/ml & $252(169-459)$ & $260(191-423)$ & 0.875 \\
\hline Peak of cTn-I, ng/ml & $77(53-185)$ & $104(61-182)$ & 0.227 \\
\hline Time to CK-MB peak, $\mathrm{h}$ & $11(9-15)$ & $10(8-14)$ & 0.116 \\
\hline Time to cTnI peak, h & $12(9-16)$ & $11(8-16)$ & 0.910 \\
\hline \multicolumn{4}{|l|}{ After surgery } \\
\hline ALT, U/1 & $19 \pm 8$ & $21 \pm 7$ & 0.511 \\
\hline AST, U/1 & $17 \pm 10$ & $18 \pm 8$ & 0.237 \\
\hline CRP, mg/l & $7.7 \pm 3$ & $8.5 \pm 2.6$ & 0.682 \\
\hline $\mathrm{BNP}, \mathrm{pg} / \mathrm{ml}$ & $896.5 \pm 102.3$ & $937.3 \pm 98.5$ & 0.149 \\
\hline White blood cell, x $10^{9} / 1$ & $11.0 \pm 3.6$ & $12.2 \pm 4.4$ & 0.446 \\
\hline Red blood cell, x10²/1 & $4.5 \pm 0.5$ & $4.6 \pm 0.4$ & 0.271 \\
\hline Hemoglobin, $g / 1$ & $142 \pm 17$ & $143 \pm 16$ & 0.862 \\
\hline Hematocrit, $\%$ & $41 \pm 4$ & $42 \pm 3$ & 0.179 \\
\hline Blood platelets, $\times 10^{9} / 1$ & $218 \pm 52$ & $217 \pm 51$ & 0.864 \\
\hline Blood urea nitrogen, mmol/l & $6.3 \pm 1.9$ & $6.0 \pm 1.7$ & 0.142 \\
\hline Serum creatinine, $\mu \mathrm{mol} / 1$ & $83.2 \pm 20.2$ & $83.5 \pm 24$ & 0.357 \\
\hline Blood uric acid, $\mu \mathrm{mol} / 1$ & $326 \pm 108$ & $303 \pm 91$ & 0.226 \\
\hline Blood sugar, mmol/1 & $8.7 \pm 2.3$ & $9.0 \pm 3$ & 0.073 \\
\hline Triglyceride, mmol/l & $1.8 \pm 1.6$ & $1.7 \pm 1.2$ & 0.557 \\
\hline Total cholesterol, mmol/1 & $4.7 \pm 1$ & $4.5 \pm 1$ & 0.315 \\
\hline High-density lipoprotein, mmol/l & $1.1 \pm 0.4$ & $1.1 \pm 0.3$ & 0.782 \\
\hline Low-density lipoprotein, mmol/1 & $2.9 \pm 0.9$ & $2.7 \pm 0.8$ & 0.163 \\
\hline
\end{tabular}

Data are presented as mean \pm standard deviation or median (interquartile range). $\mathrm{CR}$, complete revascularization; CP, conservative pharmacotherapy; AUC, area under the curve; CK-MB, creatine kinase-MB; cTn-I, cardiac troponin I; ALT, alanine aminotransferase; AST, glutamic oxaloacetic transaminase; CRP, C-reactive protein; BNP, brain natriuretic peptide. 
Table IV. Clinical outcomes during the follow-up.

\begin{tabular}{|c|c|c|c|c|c|c|}
\hline \multirow[b]{2}{*}{ Outcome } & \multicolumn{2}{|c|}{180 days follow-up } & \multirow[b]{2}{*}{ P-value } & \multicolumn{2}{|c|}{360 days follow-up } & \multirow[b]{2}{*}{ P-value } \\
\hline & CR group & $\mathrm{CP}$ group & & CR group & $\mathrm{CP}$ group & \\
\hline \multicolumn{7}{|l|}{ Primary outcome, n (\%) } \\
\hline MACE & $4(2.7)$ & $12(7.6)$ & 0.055 & $9(6.1)$ & $20(12.7)$ & 0.050 \\
\hline Mortality & $1(0.7)$ & $2(1.3)$ & 1.000 & $3(2.0)$ & $4(2.5)$ & 1.000 \\
\hline Repeated revascularization of target-vessel & $2(1.4)$ & $5(3.2)$ & 0.289 & $4(2.7)$ & $7(4.4)$ & 0.417 \\
\hline Recurrent myocardial infarction & $3(2.0)$ & $10(6.3)$ & 0.062 & $6(4.1)$ & $16(10.1)$ & 0.040 \\
\hline \multicolumn{7}{|l|}{ Secondary outcome, $\mathrm{n}(\%)$} \\
\hline Recurrent angina pectoris & $8(5.4)$ & $22(13.9)$ & 0.012 & $12(8.1)$ & $29(18.4)$ & 0.009 \\
\hline New heart failure & $2(1.4)$ & $2(1.3)$ & 1.000 & $2(1.4)$ & $3(1.9)$ & 1.000 \\
\hline Major bleeding & $8(5.4)$ & $7(4.4)$ & 0.693 & $11(7.4)$ & $10(6.3)$ & 0.703 \\
\hline
\end{tabular}

CR, complete revascularization; CP, conservative pharmacotherapy; MACE, major adverse cardiovascular events.

A

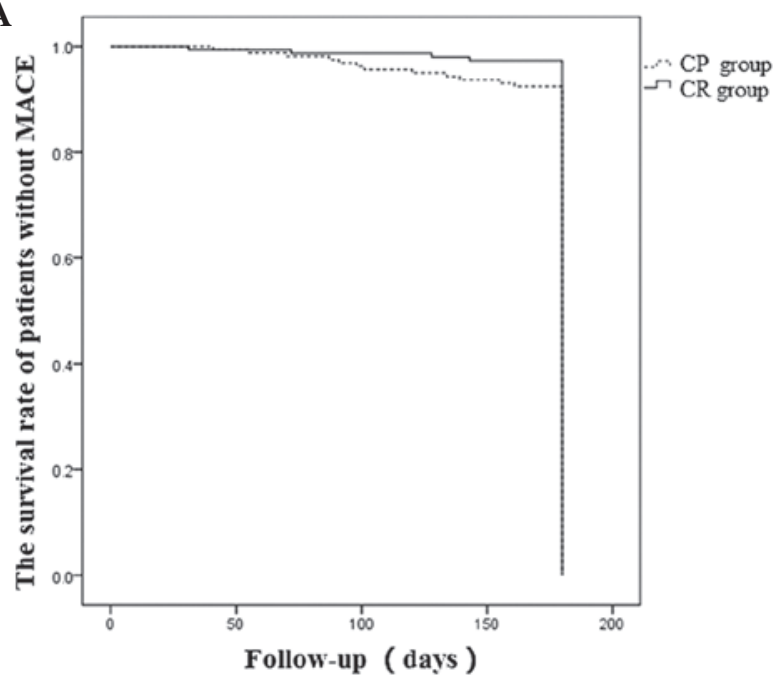

B

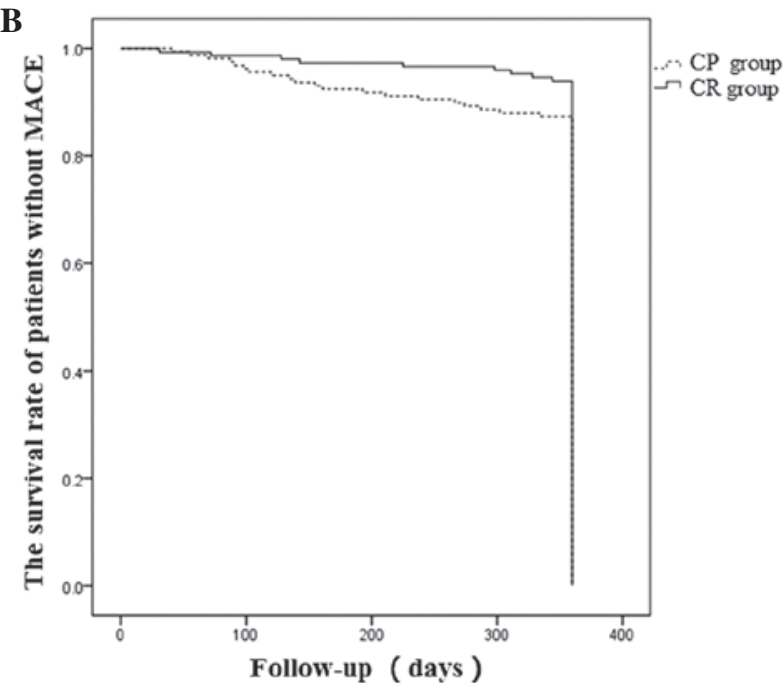

Figure 1. Kaplan-Meier curve of the MACE-free survival rate in patients with CR or CP at the (A) 180-day and (B) 360-day follow-up. The two groups showed similar MACE-free survival rates at the 180 day follow-up (97.3 vs. $92.4 \%$; P>0.05) and the MACE-free survival rate of CR group was significantly higher compared with that of $\mathrm{CP}$ group at the 360 day follow-up (93.9 vs. 87.3\%; $\mathrm{P}<0.05$ ). CR, complete revascularization; $\mathrm{CP}$, conservative pharmacotherapy; MACE, major adverse cardiovascular event.

myocardial infarction (CP group vs. CR group, 10.1 vs. $4.1 \%$; $\mathrm{P}=0.040)$. The incidence of mortality, repeated revascularization of the target-vessel, newly developed heart failure and major bleeding did not differ between the two groups (all $\mathrm{P}>0.05$ ).

Patient survival rate. The Kaplan-Meier analysis revealed no difference in the MACE-free survival rate of patients between the CR and CP groups at the 180-day follow-up (97.3 vs. $92.4 \%$; $\mathrm{P}>0.05$; Fig. 1A). However, the MACE-free survival rate of the CR group was significantly higher compared with that of the $\mathrm{CP}$ group at the 360 -day follow-up (93.9 vs. 87.3\%; P<0.05; Fig. 1B).

\section{Discussion}

In the present study, a prospective trial analysis was performed and the outcomes of SPCI and CP on non-culprit vessels in
STEMI following treatment with PPCI are compared. The results of the 360-day follow-up indicated that the incidence of MACE and recurrent myocardial infarction in the $\mathrm{CP}$ group were higher compared with those in the CR group. In addition, the incidence of recurrent angina pectoris in the $\mathrm{CP}$ group was higher compared with that in the CR group during the 180-and 360-day follow-up. At the 360-day follow-up, the MACE-free survival rate of the CR group was significantly higher compared with that in the $\mathrm{CP}$ group.

In the current study, all of the decisions regarding the treatment of patients were made based on the discretion of the clinicians involved. The performance of intra-aortic balloon counterpulsation and medical therapy were similar in the two groups, expect for the administration of nitrates. At the 360-day follow-up, repeated revascularization of the target vessel was performed in 11 patients: 4 in the CR group and 7 in the CP group. Despite no statistically significant difference, 
the findings suggested that SPCI on non-culprit lesions may result in less repeated revascularization of the target vessel.

A previous study by Di Mario et al (17) investigated the safety of the primary PCI procedure and identified that CR was not associated with excess in-hospital or 1-year MACE (defined as mortality, repeat myocardial infarction, urgent percutaneous transluminal coronary angioplasty or CABG). Qarawani et al (7) demonstrated that CR facilitated the reduced incidence of major cardiac events, including recurrent ischemia, acute heart failure, re-infarction and in-hospital mortality during PPCI. The analyses of the 360-day follow-up data in the present study revealed a significantly higher incidence of MACE in the $\mathrm{CP}$ group compared with the CR group. In addition, patients in the CR group experienced a lower incidence of recurrent angina pectoris compared with patients in the $\mathrm{CP}$ group, particularly at the 360-day follow-up. These findings are in agreement with two recent randomized trials (PRAMI and CVLPRIT) which showed reduced incidence of MACE with CR compared with $\mathrm{CP}$ in non-infarct coronary arteries with major stenosis $(10,11)$.

It has been hypothesized that for patients with STEMI, PPCI of the non-culprit vessel in the acute phase could reduce ischemia and improve survival rate (18). Vlaar et al (19) performed a pairwise meta-analysis by a primary end point of short-term mortality and identified a benefit with a staged approach in STEMI with multi-vessel disease. In addition, Bainey et al (20) performed a randomized and observational meta-analysis by adding further long-term survival (14.5 months), supporting SPCI in STEMI therapy. Furthermore, a study on the safety and efficacy of complete vs. culprit-only revascularization in patients with STEMI identified that SPCI can improve short- and long-term survival and reduce repeat PPCI (21). Consistently, patients in the present study had a higher MACE-free survival rate in the CR group compared with in the CP group at the 360 day follow-up.

A number of limitations of the current study must be addressed. First, although patients in each group were matched by demographic and baseline clinical characteristics, there was a significant difference in the age, disease time, hospital stay, body temperature and LVEDD between the patients in the two groups. Furthermore, the CP group appeared to have more severe coronary artery disease and more impaired cardiac function compared with patients in the CR group, although statistical significance was not reached. Second, significance levels were borderline in the results, which may be due to the small number of patients enrolled in the study. Third, the limited data collected during the short follow-up in this study result in the need of larger trials that can confirm the benefits of staged multivessel PPCI in patients with STEMI.

In conclusion, the results of the present study demonstrate that in patients with STEMI, SPCI for non-culprit lesions results in improved clinical outcomes compared with $\mathrm{CP}$, as evidenced by reduced incidence of subsequent MACE, recurrent myocardial infarction at 360-day follow-up, low incidence of recurrent angina pectoris at 180- and 360-day follow-up and a higher MACE-free survival rate at 360-day follow-up.

\section{Acknowledgements}

The present study was supported by the Found of the Capital Medicine Developing Research, Beijing (grant no. 2009-2076).

\section{References}

1. American College of Emergency Physicians; Society for Cardiovascular Angiography and Interventions, O'Gara PT, Kushner FG, Ascheim DD, Casey DE Jr, Chung MK, de Lemos JA, Ettinger SM, Fang JC, et al; American College of Cardiology Foundation/American Heart Association Task Force on Practice Guidelines: 2013 ACCF/AHA guideline for the management of ST-elevation myocardial infarction: A report of the American college of cardiology foundation/American heart association task force on practice guidelines. J Am Coll Cardiol 61: e78-e140, 2013.

2. de Waha S, Eitel I, Desch S, Fuernau G, Pöss J, Schuler G and Thiele H: Impact of multivessel coronary artery disease on reperfusion success in patients with ST-elevation myocardial infarction-insights from cardiac magnetic resonance imaging. J Cardiovasc Magn Reson: Dec 21, 2015.

3. Toma M, Buller CE, Westerhout CM, Fu Y, O'Neill WW, Holmes DR Jr, Hamm CW, Granger CB and Armstrong PW; APEX-AMI Investigators: Non-culprit coronary artery percutaneous coronary intervention during acute ST-segment elevation myocardial infarction: Insights from the APEX-AMI trial. Eur Heart J 31: 1701-1707, 2010

4. Jaski BE, Cohen JD, Trausch J, Marsh DG, Bail GR, Overlie PA, Skowronski EW and Smith SC Jr: Outcome of urgent percutaneous transluminal coronary angioplasty in acute myocardial infarction: Comparison of single-vessel versus multivessel coronary artery disease. Am Heart J 124: 1427-1433, 1992.

5. Sorajja P, Gersh BJ, Cox DA, McLaughlin MG, Zimetbaum P, Costantini C, Stuckey T, Tcheng JE, Mehran R, Lansky AJ, et al: Impact of multivessel disease on reperfusion success and clinical outcomes in patients undergoing primary percutaneous coronary intervention for acute myocardial infarction. Eur Heart J 28: 1709-1716, 2007.

6. King SB III, Smith SC Jr, Hirshfeld JW Jr, Jacobs AK Morrison DA, Williams DO; 2005 WRITING COMMITTEE MEMBERS, Feldman TE, Kern MJ, O'Neill WW, et al: 2007 Focused update of the ACC/AHA/SCAI 2005 guideline update for percutaneous coronary intervention: A report of the American college of cardiology/American heart association task force on practice guidelines: 2007 Writing group to review new evidence and update the ACC/AHA/SCAI 2005 guideline update for percutaneous coronary intervention, writing on behalf of the 2005 writing committee. Circulation 117: 261-295, 2008.

7. Qarawani D, Nahir M, Abboud M, Hazanov Y and Hasin Y: Culprit only versus complete coronary revascularization during primary PCI. Int J Cardiol 123: 288-292, 2008.

8. Yusuf S, Mehta SR, Chrolavicius S, Afzal R, Pogue J, Granger CB, Budaj A, Peters RJ, Bassand JP, Wallentin L, et al; OASIS-6 Trial Group: Effects of fondaparinux on mortality and reinfarction in patients with acute ST-segment elevation myocardial infarction: The OASIS- 6 randomized trial. JAMA 295: 1519-1530, 2006.

9. Sabatine MS, Cannon CP, Gibson CM, López-Sendón JL, Montalescot G, Theroux P, Claeys MJ, Cools F, Hill KA, Skene AM, et al; CLARITY-TIMI 28 Investigators: Addition of clopidogrel to aspirin and fibrinolytic therapy for myocardial infarction with ST-segment elevation. N Engl J Med 352: 1179-1189, 2005.

10. Wald DS, Morris JK, Wald NJ, Chase AJ, Edwards RJ, Hughes LO, Berry C and Oldroyd KG; PRAMI Investigators: Randomized trial of preventive angioplasty in myocardial infarction. N Engl J Med 369: 1115-1123, 2013.

11. Gershlick AH, Khan JN, Kelly DJ, Greenwood JP, Sasikaran T, Curzen N, Blackman DJ, Dalby M, Fairbrother KL, Banya W, et al: Randomized trial of complete versus lesion-only revascularization in patients undergoing primary percutaneous coronary intervention for STEMI and multivessel disease: The CvLPRIT trial. J Am Coll Cardiol 65: 963-972, 2015.

12. Stone GW, Witzenbichler B, Guagliumi G, Peruga JZ, Brodie BR, Dudek D, Kornowski R, Hartmann F, Gersh BJ, Pocock SJ, et al; HORIZONS-AMI Trial Investigators: Bivalirudin during primary PCI in acute myocardial infarction. N Engl J Med 358: 2218-2230, 2008.

13. Stone GW, Lansky AJ, Pocock SJ, Gersh BJ, Dangas G, Wong SC, Witzenbichler B, Guagliumi G, Peruga JZ, Brodie BR, et al; HORIZONS-AMI Trial Investigators: Paclitaxel-eluting stents versus bare-metal stents in acute myocardial infarction. N Engl J Med 360: 1946-1959, 2009. 
14. Mehran R, Lansky AJ, Witzenbichler B, Guagliumi G, Peruga JZ, Brodie BR, Dudek D, Kornowski R, Hartmann F, Gersh BJ, et al HORIZONS-AMI Trial Investigators: Bivalirudin in patients undergoing primary angioplasty for acute myocardial infarction (HORIZONS-AMI): 1-year results of a randomised controlled trial. Lancet 374: 1149-1159, 2009.

15. Paulus WJ, Tschöpe C, Sanderson JE, Rusconi C, Flachskampf FA, Rademakers FE, Marino P, Smiseth OA De Keulenaer G, Leite-Moreira AF, et al: How to diagnose diastolic heart failure: A consensus statement on the diagnosis of heart failure with normal left ventricular ejection fraction by the heart failure and echocardiography associations of the european society of cardiology. Eur Heart J 28: 2539-2550, 2007.

16. Cutlip DE, Windecker S, Mehran R, Boam A, Cohen DJ, van Es GA, Steg PG, Morel MA, Mauri L, Vranckx P, et al; Academic Research Consortium: Clinical end points in coronary stent trials: A case for standardized definitions. Circulation 115: 2344-2351, 2007.

17. Di Mario C, Mara S, Flavio A, Imad S, Antonio M, Anna P, Emanuela P, Stefano DS, Angelo R, Stefania C, et al: Single vs multivessel treatment during primary angioplasty: Results of the multicentre randomised HEpacoat ${ }^{\mathrm{TM}}$ for cuLPrit or multivessel stenting for acute myocardial infarction (HELP AMI) Study. Int J Cardiovas Interve 6: 128-133, 2004.
18. Hochman JS, Sleeper LA, Webb JG, Dzavik V, Buller CE, Aylward P, Col J and White HD; SHOCK Investigators: Early revascularization and long-term survival in cardiogenic shock complicating acute myocardial infarction. JAMA 295: 2511-2515, 2006.

19. Vlaar PJ, Mahmoud KD, Holmes DR Jr, van Valkenhoef G, Hillege HL, van der Horst IC, Zijlstra F and de Smet BJ: Culprit vessel only versus multivessel and staged percutaneous coronary intervention for multivessel disease in patients presenting with ST-segment elevation myocardial infarctiona pairwise and network meta-analysis. J Am Coll Cardiol 58: 692-703, 2011.

20. Bainey KR, Mehta SR, Lai T and Welsh RC: Complete vs culprit-only revascularization for patients with multivessel disease undergoing primary percutaneous coronary intervention for ST-segment elevation myocardial infarction: A systematic review and meta-analysis. Am Heart J 167: 1.e12-14.e12, 2014.

21. Sethi A, Bahekar A, Bhuriya R, Singh S, Ahmed A and Khosla S: Complete versus culprit only revascularization in acute ST elevation myocardial infarction: A meta-analysis. Catheter Cardiovasc Interv 77: 163-170, 2011. 